\title{
Different schedules of irinotecan administration: A meta-analysis
}

\author{
YI SHAO, HUI LV and DIAN-SHENG ZHONG \\ Department of Oncology, Tianjin Medical University General Hospital, Heping, Tianjin 300052, P.R. China
}

Received December 8, 2015; Accepted May 20, 2016

DOI: $10.3892 /$ mco. 2016.920

\begin{abstract}
The concept of the UDP glucuronosyltransferase family 1 member A1 genotype-directed schedule of irinotecan administration is still far from being introduced into clinical practice, and the efficacy and toxicity of irinotecan are in part schedule-dependent. The objective of the present meta-analysis was to determine the efficacy and adverse effects of 3-weekly vs. weekly irinotecan for the treatment of solid tumors. The PubMed, EMBASE and Cochrane Library databases and the search engines Google Scholar and Medical Martix were searched for randomized controlled trials to compare the two regimens of irinotecan administration. The results of the meta-analysis indicated that the 3-weekly regimen yielded a longer time to progression, while other measures of efficacy, such as the objective response rate and overall survival of patients with solid tumors were similar between the two regimens of irinotecan administration. Furthermore, the group receiving the 3-weekly regimen had a lower incidence of grade $3 / 4$ diarrhea and a higher rate of grade $3 / 4$ neutropenia compared with the group receiving the weekly regimen. However, these results require confirmation by large-sample, multicenter, randomized, controlled trials.
\end{abstract}

\section{Introduction}

Irinotecan (CPT-11), a semisynthetic derivative of camptothecin, is a topoisomerase-I inhibitor, which is active against a variety of solid tumors, including advanced colorectal, pulmonary, gastric and ovarian cancer $(1,2)$. Irinotecan is a prodrug, which is hydrolyzed by liver carboxylesterase to produce the active metabolite SN-38 (3). SN-38 is eliminated by glucuronidation, which depends on hepatic UDP glucuronosyltransferase family 1, member A1 cluster (UGTA1) enzymes (4). Genotype UGT1A1*28 has been

Correspondence to: Professor Dian-Sheng Zhong, Department of Oncology, Tianjin Medical University General Hospital, 154 Anshan Road, Heping, Tianjin 300052, P.R. China

E-mail: zhongdsh@hotmail.com; happyonco@163.com

Abbreviations: ORR, objective response rate; TTP, time to progression; OS, overall survival; RCT randomized controlled trial; ITT, intent-to-treat; RR, risk ratio; CI, confidence interval; SMD, standard mean difference

Key words: irinotecan, schedule, solid tumor, meta-analysis, colorectal carcinoma found to be associated with decreased SN-38 glucuronidation; thus, irinotecan-induced diarrhea and neutropenia may be increased in patients with the UGT1A1" $28 /$ " 28 genotype (5). While several UGT1A1 genotype-directed administration schedules of irinotecan are currently under evaluation (6-8), the concept of heritable biological marker-guided dosing is new and requires further evaluation prior to introduction in clinical practice (9).

Three schedules of irinotecan administration are currently in clinical use, namely weekly, bi-weekly and tri-weekly schedules, among which administration once every 3 weeks and a weekly 90 -min infusion are the ones most commonly used and compared $(10,11)$. The dose-limiting side effects of the two schedules are neutropenia and diarrhea. Several comparative clinical trials have been performed to investigate whether the efficacy of irinotecan is schedule-dependent and others have suggested that the toxicity profiles may be distinctive for different schedules irrespective of the genotype (5,12-18). However, these trials have not been conclusive regarding the differences between the two commonly used regimens. Therefore, a meta-analysis of all these individual data is required to determine the differences.

The objective of the present meta-analysis, which was based on all the data from randomized controlled trials (RCTs), was to compare the efficacy and toxicity profiles of the two different schedules of irinotecan, used alone or in combination with other drugs in the treatment of various solid tumors with the aim of determining the optimal administration schedule for this drug.

\section{Materials and methods}

Literature search. The electronic databases PubMed, EMBASE and Cochrane Library were searched for entries of suitable studies available prior to November, 2015 using the following search terms: (irinotecan OR CPT-11 OR Campto OR Camptosar) AND (administration OR dosage OR schedule OR regimen OR weekly). There were no language or publication status restrictions.

Inclusion criteria. Patients who were histologically or cytologically diagnosed with solid carcinomas and who had received irinotecan, alone or in combination with other chemotherapeutic drugs, were included.

Measures of outcome. The objective response rate (ORR), median time to progression (TTP), overall survival (OS) and 
Table I. Characteristics of included studies.

\begin{tabular}{|c|c|c|c|c|c|}
\hline Authors (Refs.) & Group & Tumor type & Treatment & Patients (n) & Administration schedule \\
\hline \multirow[t]{2}{*}{ Bajetta et al (12) } & $q 3 w$ & $\begin{array}{l}\text { Metastatic } \\
\text { colorectal carcinoma }\end{array}$ & First-line & 68 & $\begin{array}{l}\text { CPT-11 240-300 mg/m² } \mathrm{d} 1+ \\
\text { CAP } 1,250 \mathrm{mg} / \mathrm{m}^{2} \mathrm{~d} 2-15 \text { twice } \\
\text { daily, q3w }\end{array}$ \\
\hline & qw & & & 66 & $\begin{array}{l}\text { CPT-11 } 120-150 \mathrm{mg} / \mathrm{m}^{2} \mathrm{~d} 1,8+ \\
\text { CAP } 1,250 \mathrm{mg} / \mathrm{m}^{2} \mathrm{~d} 2-15 \text { twice } \\
\text { daily, qw }\end{array}$ \\
\hline \multirow[t]{2}{*}{ Borner et al (13) } & $\mathrm{q} 3 \mathrm{w}$ & $\begin{array}{c}\text { Metastatic } \\
\text { colorectal carcinoma }\end{array}$ & First-line & 37 & $\begin{array}{l}\text { CPT-11 240-300 mg/m² } \mathrm{d} 1+ \\
\text { CAP } 1,000 \mathrm{mg} / \mathrm{m}^{2} \mathrm{~d} 1-14 \text { twice } \\
\text { daily, } \mathrm{q} 3 \mathrm{w}\end{array}$ \\
\hline & qw & & & 38 & $\begin{array}{l}\text { CPT-11 } 70 \mathrm{mg} / \mathrm{m}^{2} \mathrm{~d} 1,8,15+ \\
\text { CAP } 1,000 \mathrm{mg} / \mathrm{m}^{2} \mathrm{~d} 1-14 \text { twice } \\
\text { daily, qw }\end{array}$ \\
\hline \multirow[t]{2}{*}{ Fuchs et al (14) } & $\mathrm{q} 3 \mathrm{w}$ & $\begin{array}{c}\text { Metastatic } \\
\text { colorectal carcinoma }\end{array}$ & Second-line & 190 & CPT-11 300-350 mg/m² d1 q3w \\
\hline & qw & & & 94 & $\begin{array}{l}\text { CPT-11 } 125 \mathrm{mg} / \mathrm{m}^{2} \text { weekly for } \\
4 \text { weeks followed by a } 2 \text {-week } \\
\text { interval }\end{array}$ \\
\hline \multirow[t]{2}{*}{ Mascarenhas et al (15) } & $\mathrm{q} 3 \mathrm{w}$ & Rhabdomyosarcoma & Second-line & 47 & $\begin{array}{l}\text { CPT-11 } 50 \mathrm{mg} / \mathrm{m}^{2} \mathrm{~d} 1-5+ \\
\text { vincristine } 1.5 \mathrm{mg} / \mathrm{m}^{2} \mathrm{~d} 1,8 \text { twice } \\
\text { daily, } \mathrm{q} 3 \mathrm{w}\end{array}$ \\
\hline & qw & & & 42 & $\begin{array}{l}\text { CPT-11 } 20 \mathrm{mg} / \mathrm{m}^{2} \mathrm{~d} 1-5 \text { of } \\
\text { weeks } 1,2,4 \text { and } 5+ \\
\text { vincristine } 1.5 \mathrm{mg} / \mathrm{m}^{2} \mathrm{~d} 1,8 \\
\text { twice daily, qw }\end{array}$ \\
\hline \multirow[t]{2}{*}{ Perez et al (16) } & $\mathrm{q} 3 \mathrm{w}$ & $\begin{array}{c}\text { Metastatic } \\
\text { breast cancer }\end{array}$ & $\begin{array}{l}\text { Second-line } \\
\text { or beyond }\end{array}$ & 51 & CPT-11 $240 \mathrm{mg} / \mathrm{m}^{2} \mathrm{~d} 1 \mathrm{q} 3 \mathrm{w}$ \\
\hline & qw & & & 53 & $\begin{array}{l}\text { CPT-11 } 100 \mathrm{mg} / \mathrm{m}^{2} \mathrm{~d} 1 \\
\text { weekly for } 4 \text { weeks followed by a } \\
\text { 2-week interval }\end{array}$ \\
\hline \multirow[t]{2}{*}{ Schoemaker et al (17) } & $\mathrm{q} 3 \mathrm{w}$ & $\begin{array}{c}\text { Metastatic } \\
\text { colorectal carcinoma }\end{array}$ & Second-line & 41 & CPT-11 350 mg/m² d1 q3w \\
\hline & qw & & & 37 & $\begin{array}{l}\text { CPT-11 } 125 \mathrm{mg} / \mathrm{m}^{2} \mathrm{~d} 1 \text { weekly } \\
\text { for } 4 \text { weeks followed by a } \\
\text { 2-week interval }\end{array}$ \\
\hline \multirow[t]{2}{*}{ Tsavaris et al (18) } & $\mathrm{q} 3 \mathrm{w}$ & $\begin{array}{c}\text { Advanced } \\
\text { colorectal carcinoma }\end{array}$ & Second-line & 60 & CPT-11 350 mg/m² d1 q3w \\
\hline & qw & & & 60 & CPT-11 $175 \mathrm{mg} / \mathrm{m}^{2} \mathrm{~d} 1,10 \mathrm{qw}$ \\
\hline
\end{tabular}

CPT-11, irinotecan; CAP, capecitabine; qw3, every 3 weeks; qw, every week.

the incidence of adverse effects, including neutropenia and diarrhea, were assessed in the present study.

Regimens. The regimens compared in the present meta-analysis were 3-weekly vs. weekly irinotecan for the treatment of solid tumors.

Data extraction. The titles and abstracts of all identified trials were screened by two authors independently for inclusion criteria. Disagreements were resolved by consensus. The same two authors extracted data independently using standard data extraction forms.
Quality assessment of the studies. The quality of the studies was assessed by two independent authors. Discrepancies were resolved by discussion with another author. Quality was assessed based on randomization, allocation concealment, blinding (participants, investigators, outcome assessors and data analysis), loss to follow-up and intent-to-treat (ITT) analysis. The trials were graded as A, B or C following the criteria of Cochrane with the aim of assessing all types of bias (19).

Statistical analysis. Quantitative meta-analyses were performed to compare the efficacy and adverse effects between the 3 -weekly and weekly groups. Forest plots were 
Table II. Quality assessment of included studies.

\begin{tabular}{lcccc}
\hline Authors (Refs.) & Randomization & $\begin{array}{c}\text { Allocated } \\
\text { concealment }\end{array}$ & Blinding & $\begin{array}{c}\text { Loss to follow-up } \\
\text { and dropout }\end{array}$ \\
\hline Bajetta et al $(12)$ & Adequate & n.s. & n.s. & Yes without ITT analysis \\
Borner et al $(13)$ & n.s. & n.s. & n.s. & No \\
Fuchs et al $(14)$ & Adequate & n.s. & n.s. & Yes with ITT analysis \\
Mascarenhas et al $(15)$ & n.s. & n.s. & n.s. & No \\
Perez et al $(16)$ & Adequate & n.s. & n.s. & No \\
Schoemaker et al $(17)$ & n.s. & n.s. & Not used & Yes with ITT analysis \\
Tsavaris et al $(18)$ & Adequate & n.s. & n.s. & No \\
\hline
\end{tabular}

ITT, intent-to-treat; n.s., not specified.

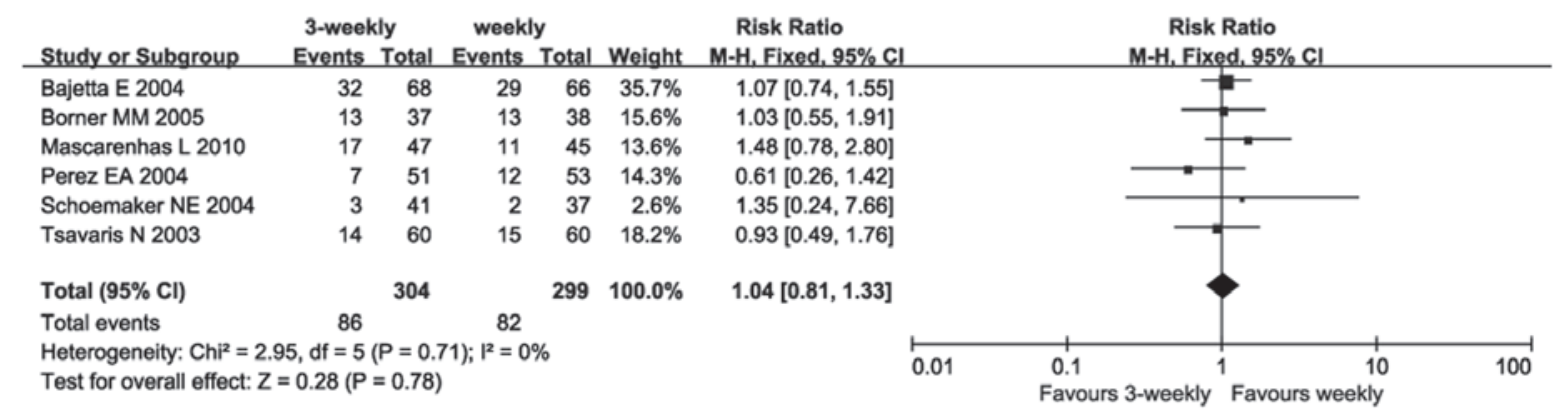

Figure 1. Objective response rate. CI, confidence interval; M-H, Mantel-Haenszel model; df, degree of freedom.

generated using Review Manager software version 5.3 (http:// tech.cochrane.org/revman/download). The risk ratio (RR) was calculated along with its $95 \%$ confidence intervals (CI) for dichotomous data and the standard mean difference (SMD) was used for continuous outcomes. Statistical heterogeneity between studies was assessed by means of $\mathrm{I}^{2}$ statistics. $\mathrm{I}^{2}<25 \%$ was considered to indicate a low level of heterogeneity, $\mathrm{I}^{2}=25-50 \%$ moderate-level and $\mathrm{I}^{2}>50 \%$ high-level heterogeneity. A fixed-effects model was used for calculations if there was no significant heterogeneity, while a random-effects model was applied if clinical and methodological heterogeneity were present. All statistical outcomes were two-sided and the significance threshold was set at $\mathrm{P}<0.05$.

\section{Results}

Study selection. The literature search yielded 1,821 studies, of which 1,814 were excluded due to irrelevant content, not meeting the inclusion criteria, repeated content or non-randomization. Finally, 7 RCTs (12-18), comprising a total of 884 patients, were included in the present meta-analysis. Among these, 3 RCTs included regimens in which irinotecan was used in combination with other therapeutic drugs $(12,13,15)$ and 4 RCTs used irinotecan alone (14,16-18).

Characteristics of included studies and quality assessment. The characteristics of the studies assessed are listed in Table I and the results of quality assessment are shown in Table II. The overall quality of the studies was moderate to low (grades B and C). All 7 studies were randomized (12-18). Bajetta et al (12) used a computer-generated randomization list, Fuchs et al (14) used electronical randomization, Perez et al (16) used a dynamic allocation procedure and Tsavaris et al (18) used closed envelopes, while the method of randomization was not specified in the remaining 3 studies $(13,15,17)$. None of the 7 studies mentioned allocated concealment. One study did not use blinding (17), while blinding was not mentioned in the remaining 6 studies $(12-16,18)$. One study reported on loss to follow-up without ITT analysis (12) and 2 studies reported on loss to follow-up and performed ITT analysis $(14,17)$, while the remaining studies did not describe loss to follow-up $(13,15,16,18)$.

\section{Efficacy}

ORR. Six trials provided an ORR $(12,14,15-18)$. As there was no heterogeneity between these trials $\left(\mathrm{P}=0.71 ; \mathrm{I}^{2}=0 \%\right)$, a fixed-effects model was used. The meta-analysis revealed no significant difference between the 3-weekly and weekly groups regarding ORR ( $\mathrm{RR}=1.04$; 95\% CI: 0.81-1.33; $\mathrm{P}=0.78)$ (Fig. 1).

TTP. Five trials reported on TTP $(13,14,16-18)$. As there was no heterogeneity between these trials $\left(\mathrm{P}=0.32 ; \mathrm{I}^{2}=14 \%\right)$, a fixed-effects model was used. The meta-analysis revealed a significant difference in favor of the 3-weekly group regarding TTP (SMD=-0.89; 95\% CI: -1.66 to -0.13 ); $\mathrm{P}=0.02$ (Fig. 2).

$O S$. Five trials $(13,14,16-18)$ reported on OS. Due to heterogeneity among these trials $\left(\mathrm{P}=0.07 ; \mathrm{I}^{2}=54 \%\right)$, a random-effects model was used. The meta-analysis revealed no significant difference between the 3 -weekly and weekly groups ( $\mathrm{SMD}=-0.10$, 95\% CI: -2.53 to $2.34, \mathrm{P}=0.94$ ) (Fig. 3). 


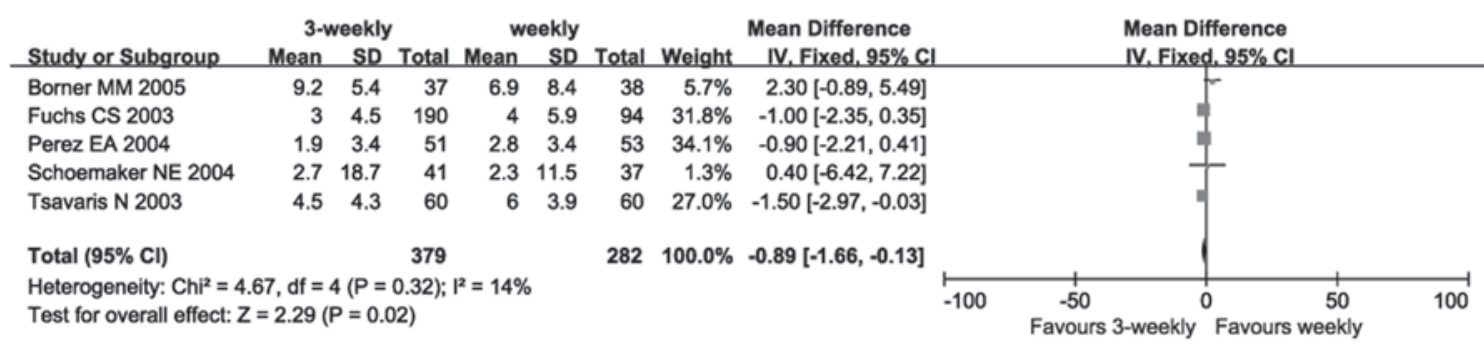

Figure 2. Time to progression. SD, standard deviation; df, degree of freedom; CI, confidence interval.

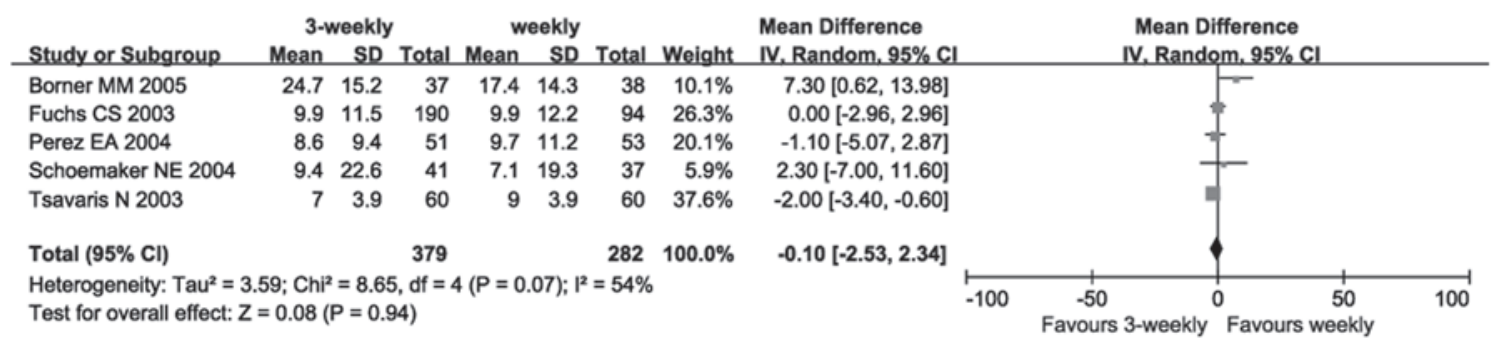

Figure 3. Overall survival. SD, standard deviation; df, degree of freedom; CI, confidence interval.

\begin{tabular}{|c|c|c|c|c|c|c|c|c|c|c|}
\hline Study or Subgroup & $\begin{array}{l}\text { 3-week } \\
\text { Events }\end{array}$ & $\begin{array}{l}\text { y } \\
\text { Iotal }\end{array}$ & $\begin{array}{l}\text { weekly } \\
\text { Events }\end{array}$ & Total & Weight & $\begin{array}{l}\text { Risk Ratio } \\
\mathrm{M}-\mathrm{H} \text {. Fixed, } 95 \% \mathrm{Cl}\end{array}$ & & $\begin{array}{r}\text { Risk F } \\
\text { M-H,Fixe }\end{array}$ & $\begin{array}{l}\text { Ratio } \\
\text { ed. } 95 \% \mathrm{Cl}\end{array}$ & \\
\hline Bajetta E 2004 & 8 & 68 & 9 & 66 & $6.8 \%$ & $0.86[0.35,2.10]$ & & & & \\
\hline Borner MM 2005 & 7 & 37 & 13 & 38 & $9.5 \%$ & $0.55[0.25,1.23]$ & & & & \\
\hline Fuchs CS 2003 & 36 & 190 & 34 & 94 & $33.6 \%$ & $0.52[0.35,0.78]$ & & $7-$ & & \\
\hline Mascarenhas L 2010 & 6 & 47 & 9 & 42 & $7.0 \%$ & $0.60[0.23,1.53]$ & & & & \\
\hline Perez EA 2004 & 6 & 51 & 9 & 53 & $6.5 \%$ & $0.69[0.27,1.81]$ & & & & \\
\hline Schoemaker NE 2004 & 4 & 41 & 9 & 37 & $7.0 \%$ & $0.40[0.13,1.19]$ & & & & \\
\hline Tsavaris N 2003 & 25 & 60 & 40 & 60 & $29.6 \%$ & $0.63[0.44,0.89]$ & & $\rightarrow-$ & & \\
\hline Total $(95 \% \mathrm{Cl})$ & & 494 & & 390 & $100.0 \%$ & $0.59[0.47,0.74]$ & & & & \\
\hline Total events & 92 & & 123 & & & & & & & \\
\hline \multicolumn{7}{|c|}{$\begin{array}{l}\text { Heterogeneity: } \mathrm{Ch}^{2}=1.76, \mathrm{df}=6(P=0.94) ; I^{2}=0 \% \\
\text { Test for overall effect: } Z=4.62(P<0.00001)\end{array}$} & 0.01 & $\begin{array}{ll}0.1 & 1 \\
\text { Favours 3-weekly }\end{array}$ & $\begin{array}{l}10 \\
\text { Favours weekly }\end{array}$ & 100 \\
\hline
\end{tabular}

Figure 4. Incidence of grade-3/4 diarrhea. M-H, Mantel-Haenszel model; df, degree of freedom; CI, confidence interval.

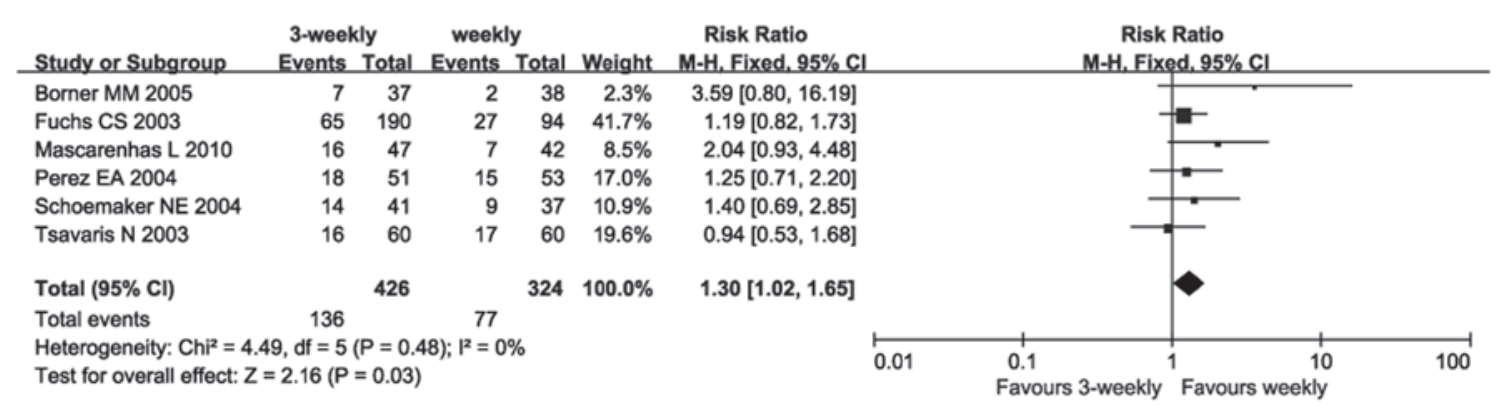

Figure 5. Incidence of grade-3/4 neutropenia. M-H, Mantel-Haenszel model; df, degree of freedom; CI, confidence interval.

\section{Adverse effects}

Diarrhea. All 7 trials (12-18) reported on the incidence of diarrhea. As there was no heterogeneity between the trials $(\mathrm{P}=0.94$; $\mathrm{I}^{2}=0 \%$ ), a fixed-effects model was used. The meta-analysis revealed that the incidence of diarrhea in the 3-weekly group was significantly lower compared with that in the weekly group ( $\mathrm{RR}=0.59$; 95\% CI: 0.47-0.74; $\mathrm{P}<0.00001)$ (Fig. 4).

Neutropenia. Six trials reported on the incidence of neutropenia (13-18). As there was no heterogeneity between these trials $\left(\mathrm{P}=0.48 ; \mathrm{I}^{2}=0 \%\right)$, a fixed-effects model was used.
The meta-analysis revealed that the incidence of neutropenia in the 3-weekly group was significantly higher compared with that in the weekly group $(\mathrm{RR}=1.30 ; 95 \% \mathrm{CI}$ : $1.02-1.65$; $\mathrm{P}=0.03$ ) (Fig. 5).

\section{Discussion}

The results of the present meta-analysis revealed that the 3-weekly and weekly regimens of irinotecan administration had a similar efficacy interms of ORR and OS, while the TTP 
tended to be longer with the 3-week regimen. Furthermore, the 3-weekly group had a lower incidence of grade 3/4 diarrhea compared with the weekly group, while the incidence of grade $3 / 4$ neutropenia was higher in the 3 -weekly group.

Irinotecan is a widely used chemotherapeutic drug that is effective against several solid tumors, with a single-agent response rate of $12-50 \%(20,21)$. The primary toxicities of irinotecan are diarrhea and neutropenia, the severity of which has been shown to be partly associated with UGT1A1*28, a germline genetic variant affecting the elimination of SN-38. Several trials and a meta-analysis demonstrated that the UGT1A1*28/*28 genotype is associated with an increased risk of neutropenia and diarrhea, and that this association was dose-dependent $(5,22)$. Genotype-directed dosing has been investigated by a series of studies (6-8); however, its integration into the clinical practice remains scant and this drug is still dosed by body surface area according to almost all guidelines. Furthermore, SN-38 accounts for only $14 \%$ of the total interindividual variability in the absolute neutrophil count nadir (9), suggesting that additional factors may lead to neutropenia. Among the factors contributing to irinotecan-related toxicity, schedule-dependent toxicity has been most reliably confirmed (23). The present meta-analysis suggested that the toxicity patterns of the two different schedules were somewhat distinctive. The 3-weekly regimen was associated with a lower incidence of diarrhea but a higher rate of neutropenia compared with the weekly regimen. Furthermore, the 3-weekly regimen was superior in terms of TTP, although the OS was similar between the two regimens. Thus, the irinotecan treatment schedule should be selected according to the characteristics, physical status, convenience and preference of each patient.

The trials assessed in the present meta-analysis were heterogeneous in terms of OS. Treatment response not only depends on the chemotherapeutic schedule, but is also tumor type-dependent. Among the included trials, 5 investigated advanced or metastatic colorectal carcinoma (12-14,17,18), 1 investigated rhabdomyosarcoma (15) and 1 was on breast cancer (16). Furthermore, in 2 of the studies, irinotecan was used as first-line therapy in combination with capecitabine $(12,13)$, while in the remaining studies, irinotecan monotherapy was used as a second- or further-line treatment. Moreover, OS tends to be affected by the subsequent treatment and several other unforeseen factors. Therefore, the differences in tumor type, treatment modality/schedule and patient characteristics may all contribute to the heterogeneity observed. In this context, ORR and TTP may reflect the acute efficacy of a therapy more accurately, in which heterogeneity was acceptable or absent. Mascarenhas et al (15) investigated rhabdomyosarcoma patients aged $<21$ years; therefore, a sensitivity analysis was performed. The result demonstrated that there was no difference in the overall effect with or without this trial.

The quality of the studies included in the present meta-analysis was relatively low, which may limit the reliability of the conclusions. Three trials did not report the details of randomization $(13,15,17)$, whereas none of the trials specified whether allocated concealment was performed. Furthermore, 6 of the studies did not mention blinding, whereas the remaining study specified that blinding was not performed (17). In addition, 1 study reported loss to follow-up, while no ITT analysis was performed (12). All these factors may have led to selection, performance, measurement and attrition biases. Of the 7 the included trials, 3 were from the
USA (14-16) and 4 from Europe $(12,13,17,18)$, which may reduce the universality of the results. The relatively small sample size and the fact that most of the studies were relatively old (>10 years) are also considered as limitations of the present meta-analysis. Therefore, it is recommended that more RCTs of high quality from different countries and with improved design are performed in the future.

In conclusion, the present meta-analysis suggested that, compared to the weekly regimen of irinotecan, the 3-weekly regimen yielded a similar ORR and OS, but a longer TTP. The two regimens exhibited distinctly different toxicity profiles: While the 3-weekly regimen was associated with a lower incidence of diarrhea, it had a higher rate of neutropenia compared with the weekly regimen. Thus, when selecting an irinotecan treatment schedule, cost-effectiveness, the patients' performance status and convenience should be taken into consideration.

\section{References}

1. Pitot HC, Wender DB, O'Connell MJ, Schroeder G, Goldberg RM, Rubin J, Mailliard JA, Knost JA, Ghosh C, Kirschling RJ, et al: Phase II trial of irinotecan in patients with metastatic colorectal carcinoma. J Clin Oncol 15: 2910-2919, 1997.

2. Vanhoefer U, Harstrick A, Achterrath W, Cao S, Seeber S and Rustum YM: Irinotecan in the treatment of colorectal cancer: Clinical overview. J Clin Oncol 19: 1501-1518, 2001.

3. Rivory LP, Bowles MR, Robert J and Pond SM: Conversion of irinotecan (CPT-11) to its active metabolite, 7-ethyl-10-hydroxycamptothecin (SN-38), by human liver carboxylesterase. Biochem Pharmacol 52: 1103-1111, 1996.

4. Iyer L, King CD, Whitington PF, Green MD, Roy SK, Tephly TR, Coffman BL and Ratain MJ: Genetic predisposition to the metabolism of irinotecan (CPT-11). Role of uridine diphosphate glucuronosyltransferase isoform 1A1 in the glucuronidation of its active metabolite (SN-38) in human liver microsomes. J Clin Invest 101: 847-854, 1998.

5. Hu ZY, Yu Q, Pei Q and Guo C: Dose-dependent association between UGT1A1*28 genotype and irinotecan-induced neutropenia: Low doses also increase risk. Clin Cancer Res 16: 3832-3842, 2010

6. Innocenti F, Schilsky RL, Ramírez J, Janisch L, Undevia S, House LK, Das S, Wu K, Turcich M, Marsh R, et al: Dose-finding and pharmacokinetic study to optimize the dosing of irinotecan according to the UGT1A1 genotype of patients with cancer. J Clin Oncol 32: 2328-2334, 2014.

7. Kim KP, Kim HS, Sym SJ, et al: A UGT1A1"28 and *6 genotype-directed phase I dose-escalation trial of irinotecan with fixed-dose capecitabine in Korean patients with metastatic colorectal cancer. Cancer Chemother Pharmacol 71: 1609-1617, 2013.

8. Goetz MP, McKean HA, Reid JM, et al: UGT1A1 genotype-guided phase I study of irinotecan, oxaliplatin, and capecitabine. Invest New Drugs 31: 1559-1567, 2013.

9. Phelps MA and Sparreboom A: Irinotecan pharmacogenetics: A finished puzzle? J Clin Oncol 32: 2287-2289, 2014.

10. Rothenberg ML, Eckardt JR, Kuhn JG, Burris HA III, Nelson J, Hilsenbeck SG, Rodriguez GI, Thurman AM, Smith LS, Eckhardt SG, et al: Phase II trial of irinotecan in patients with progressive or rapidly recurrent colorectal cancer. J Clin Oncol 14: 1128-1135, 1996.

11. Armand JP, Extra YM, Catimel G, Abigerges D, Marty M and Clavel M: Rationale for the dosage and schedule of CPT-11 (irinotecan) selected for phase II studies, as determined by European phase I studies. Ann Oncol 7: 837-842, 1996.

12. Bajetta E, Di Bartolomeo M, Mariani L, Cassata A, Artale S, Frustaci S, Pinotti G, Bonetti A, Carreca I, Biasco G, et al: Randomized multicenter phase II trial of two different schedules of irinotecan combined with capecitabine as first-line treatment in metastatic colorectal carcinoma. Cancer 100: 279-287, 2004.

13. Borner MM, Bernhard J, Dietrich D, et al: A randomized phase II trial of capecitabine and two different schedules of irinotecan in first-line treatment of metastatic colorectal cancer: Efficacy, quality-of-life and toxicity. Ann Oncol 16: 282-288, 2005. 
14. Fuchs CS, Moore MR, Harker G, Villa L, Rinaldi D and Hecht JR: Phase III comparison of two irinotecan dosing regimens in second-line therapy of metastatic colorectal cancer. J Clin Oncol 21: 807-814, 2003.

15. Mascarenhas L, Lyden ER, Breitfeld PP, et al: Randomized phase II window trial of two schedules of irinotecan with vincristine in patients with first relapse or progression of rhabdomyosarcoma: A report from the Children's Oncology Group. J Clin Oncol 28 : 4658-4663, 2010.

16. Perez EA, Hillman DW, Mailliard JA, Ingle JN, Ryan JM Fitch TR, Rowland KM, Kardinal CG, Krook JE, Kugler JW and Dakhil SR: Randomized phase II study of two irinotecan schedules for patients with metastatic breast cancer refractory to an anthracycline, a taxane, or both. J Clin Oncol 22: 2849-2855, 2004.

17. Schoemaker NE, Kuppens IE, Moiseyenko V, Glimelius B, Kjaer M, Starkhammer H, Richel DJ, Smaaland R, Bertelsen K, Poulsen JP, et al: A randomised phase II multicentre trial of irinotecan (CPT-11) using four different schedules in patients with metastatic colorectal cancer. Br J Cancer 91: 1434-1441, 2004.

18. Tsavaris N, Ziras N, Kosmas C, Giannakakis T, Gouveris P, Vadiaka M, Dimitrakopoulos A, Karadima D, Rokana S, Papalambros E, et al: Two different schedules of irinotecan (CPT-11) in patients with advanced colorectal carcinoma relapsing after a 5-fluorouracil and leucovorin combination. A randomized study. Cancer Chemother Pharmacol 52: 514-519, 2003.

19. Higgins JP, Altman DG, Gøtzsche PC, Jüni P, Moher D, Oxman AD, Savovic J, Schulz KF, Weeks L, Sterne JA, et al The Cochrane Collaboration's tool for assessing risk of bias in andomized trials. BMJ 18: d5928, 2011.
20. Rothenberg ML, Cox JV, DeVore RF, Hainsworth JD, Pazdur R, Rivkin SE, Macdonald JS, Geyer CE Jr, Sandbach J, Wolf DL, et al: A multicenter, phase II trial of weekly irinotecan (CPT-11) in patients with previously treated colorectal carcinoma. Cancer 85: 786-795, 1999.

21. Rougier P, Van Cutsem E, Bajetta E, Niederle N, Possinger K, Labianca R, Navarro M, Morant R, Bleiberg H, Wils J, et al: Randomised trial of irinotecan versus fluorouracil by continuous infusion after fluorouracil failure in patients with metastatic colorectal cancer. Lancet 352: 1407-1412, 1998.

22. Hoskins JM, Goldberg RM, Qu P, Ibrahim JG and McLeod HL: UGT1A $1 * 28$ genotype and irinotecan-induced neutropenia: Dose matters. J Natl Cancer Inst 99: 1290-1295, 2007.

23. Masuda N, Kudoh S and Fukuoka M: Irinotecan (CPT-11): Pharmacology and clinical applications. Crit Rev Oncol Hematol 24: 3-26, 1996. 